\title{
Magnitude e Condições de Reprodução Econômica dos Agricultores Familiares Pobres no Semiárido Brasileiro: evidências a partir do Rio Grande do Norte ${ }^{1}$
}

\author{
Joacir Rufino de Aquino ${ }^{2}$ e Marta Aurélia Dantas de Lacerda ${ }^{3}$
}

Resumo: O objetivo deste artigo é analisar a dimensão e as condições de reprodução econômica dos agricultores pobres potencialmente enquadráveis no Grupo B do Programa Nacional de Fortalecimento da Agricultura Familiar (Pronaf) no estado do Rio Grande do Norte. Para tanto, foram utilizadas informações obtidas por meio do processamento de "tabulações especiais" da segunda apuração do Censo Agropecuário 2006 do IBGE. Em linhas gerais, o trabalho mostra que os agricultores familiares do Grupo B - aqueles com rendimentos anuais até R\$ 3 mil - somavam 42.234 estabelecimentos, representando algo em torno de $60 \%$ dos 71.210 agricultores familiares norte-rio-grandenses recenseados em 2006. O baixo valor da produção agropecuária gerado anualmente por esse contingente de produtores é determinado por "múltiplas carências produtivas" (escassez de terra, água, educação, tecnologias, crédito e assistência técnica), o que torna sua reprodução econômica dependente de outras fontes de receitas vindas de fora da propriedade, com especial destaque para as rendas das aposentadorias rurais e dos demais programas sociais do governo. Essas e outras evidências permitem avançar na compreensão da heterogeneidade social e pobreza que caracteriza a agropecuária no semiárido brasileiro, fornecendo subsídios relevantes para novas pesquisas na área e para (re)orientar o foco das políticas públicas de desenvolvimento rural.

Palavras-chaves: Agricultores familiares pobres, Pronaf, desenvolvimento rural.

1. Os autores agradecem os comentários e sugestões dos professores Sergio Schneider (UFRGS) e Rogério Cruz (UFRN), os quais foram fundamentais para aprimorar aspectos importantes da análise empreendida no texto. Erros e omissões que persistirem no conteúdo apresentado são unicamente de nossa responsabilidade.

2. Mestre em Economia Rural e Regional (UFCG). Professor Adjunto III do Departamento de Economia da Universidade do Estado do Rio Grande do Norte (UERN), Campus de Assú. E-mail: joaciraquino@yahoo.com.br.

3. Mestra em Economia (UFPB). Professora Adjunta I do Departamento de Economia da Universidade do Estado do Rio Grande do Norte (UERN), Campus de Assú. E-mail: martadantas@yahoo.com.br. 


\begin{abstract}
The purpose of this paper is to analyze the dimension and the conditions of economic reproduction of the poor farmers potentially classifiable in Group B of the National Program for Strengthening Family Farm (Pronaf), in Rio Grande do Norte State. To this end, was used information obtained through processing "special tabulation" of the second count of the Agricultural Census in 2006, conducted by IBGE. In general, the work shows that the family farmers in Group B - those with annual incomes until \$3000 - totaled 42,234 establishments, representing roughly $60 \%$ of the 71,210 farmers in Rio Grande do Norte census in 2006. The low value of agricultural production generated annually by this number of producers is determined by "multiple productive deficiencies" (scarcity of land, water, education, technology, credit and technical assistance), which makes its economic reproduction dependent on other sources of revenue from outside the property, with particular emphasis on incomes of rural pensions and other government social programs. These and other evidences allow advanced understanding of poverty and social heterogeneity that characterizes agriculture in the Brazilian semiarid region by providing relevant information for further research in the area and to (re) orient the focus of the public policies for rural development.
\end{abstract}

Key-words: Poor family farmers, Pronaf, rural development.

Classificação JEL: Q1, Q15, Q18.

\section{Introdução}

A agricultura familiar é uma forma de produção e trabalho bastante presente nas áreas rurais do Brasil. No âmbito acadêmico, o debate sobre o seu papel na estrutura agrária nacional ganhou ânimo novo com a publicação, pelo Instituto Brasileiro de Geografia Estatística (IBGE), do Censo Agropecuário 2006. Essa pesquisa, que contou com a colaboração de técnicos do Ministério do Desenvolvimento Agrário (MDA), possibilitou o preenchimento de uma importante lacuna de informações oficiais para as políticas de desenvolvimento rural, ao investigar "quantos são, onde estão, como e o que produzem os agricultores familiares no País" (IBGE, 2009, p. 13).

Os números daquele Censo, desde a divulgação dos resultados da primeira apuração realizada em 2009, têm sido usados com frequência por muitos pesquisadores para evidenciar a importância socioeconômica do universo da agricultura familiar comparativamente ao segmento não familiar ou patronal. Del Grossi e Marques (2010), por exemplo, destacam que os 4,3 milhões de estabelecimentos familiares mapeados pelo recenseamento do IBGE, representam $84 \%$ das unidades produtivas do País, as quais são responsáveis por $38 \%$ do valor da produção agropecuária e $74 \%$ da mão de obra empregada no campo.
No que diz respeito à região Nordeste, onde estão concentrados metade dos agricultores familiares brasileiros, Coêlho (2010) e o Instituto Nacional do Semiárido (INSA, 2014) também recorreram aos dados censitários para evidenciar que a agricultura familiar é o segmento predominante no contexto agrário regional, particularmente na zona de abrangência do semiárido. Em todos os estados nordestinos, conforme asseveram tais estudos, o segmento familiar é responsável pela maior parte das ocupações e pela produção dos principais alimentos básicos produzidos nas unidades de produção agropecuária.

Os referidos indicadores têm contribuído para alimentar o debate político e auxiliar os movimentos sociais na disputa por fundos públicos (GRAZIANO DA SILVA, 2010). Entretanto, deve-se enfatizar que eles têm escopo analítico limitado, pois, como explica Navarro (2010), a expressão generalizante "agricultura familiar" oculta a heterogeneidade social e produtiva existente nas regiões rurais do Brasil. Ademais, é preciso destacar que a situação dos agricultores familiares brasileiros identificados pelo Censo de 2006 não é inteiramente favorável como sugere o indicador agregado do levantamento do IBGE (DELGADO, 2005; GUANZIROLI, BUAINAIN e DI SABBATO, 2012).

De fato, a partir da análise preliminar de "tabulações especiais" das estatísticas censitá- 
rias publicadas apenas recentemente, Aquino et al. $(2011,2014)$ evidenciam que os agricultores familiares pobres do Grupo B - aqueles com rendimentos anuais até $R \$ 3$ mil e que fazem parte do público potencial da linha de microcrédito do Programa Nacional de Fortalecimento da Agricultura Familiar (Pronaf) - ainda constituem o segmento majoritário no campo. Segundo esses autores, existiam 2.416.127 estabelecimentos com esse perfil no Brasil, representando mais da metade dos agricultores familiares do País. A ampla maioria deles se concentra no Nordeste (1.567.863, ou 65\% do total), onde, de cada 100 estabelecimentos familiares, ao menos 72 eram do Grupo B. A região Sudeste, puxada pelos 242.595 estabelecimentos de Minas Gerais, ocupa a segunda posição no ranking com $51 \%$ dos seus agricultores familiares enquadrados no estrato mais pobre da agropecuária nacional. Já os percentuais registrados na região Sul foram menos significativos, mas, mesmo contando com a parcela mais consolidada da agricultura familiar nacional, foram identificados em seu espaço territorial cerca de 270 mil estabelecimentos de baixa renda em 2006.

O enorme contingente de agricultores do Grupo B é composto por produtores extremamente pobres que foram incluídos no Pronaf somente em 2000 para serem atendidos por uma linha especial de microcrédito produtivo. Em 2006, período de referência do último Censo Agropecuário, o grupo de "pronafianos" pobres englobava todos os produtores com rendimentos anuais até R\$ 3 mil. Atualmente, conforme as normas do Plano Safra 2013/2014, ele abrange todos os agricultores familiares com rendas até R\$ 20 mil, constituindo o público preferencial do Programa de Microcrédito Produtivo Rural do Banco do Nordeste do Brasil (BNB), o Agroamigo, e das demais políticas sociais do governo (MAIA, ROITMAN e DE CONTI, 2012; MDA/SAF, 2013).

Em termos analíticos, os produtores do Grupo B podem ser nomeados também como agricultores familiares de subsistência. Adota-se esta definição, seguindo o conceito desenvolvido por Delgado (2005), não por eles produzirem ali- mentos unicamente para o autoconsumo, mas por sua capacidade de gerar pouco ou nenhum excedente monetário. Essa categoria de agricultores foi historicamente excluída ao longo da trajetória da economia brasileira e, inclusive, ocupa um lugar marginal no âmbito do Pronaf, que tem apoiado preferencialmente os segmentos mais capitalizados da agricultura familiar (BELIK, 2014; CORRÊA e ORTEGA, 2002; GUANZIROLI, 2007; MATTEI, 2011; SOUZA et al., 2013). Como já foi lembrado, até pouco tempo era praticamente impossível identificá-los, pois eles eram invisíveis do ponto de vista das estatísticas oficiais. Mas, a partir do final de 2012, com o lançamento da nova base de dados do IBGE/Sidra, que adota as normas de enquadramento do público-alvo do Pronaf como critério de estratificação do segmento familiar, tornou-se possível estudá-los em mais detalhes nas diferentes escalas territoriais do País, o que abre uma nova fronteira de pesquisa ainda pouco explorada pelos pesquisadores brasileiros.

Neste contexto, visando contribuir com o debate sobre o tema, o objetivo deste artigo é quantificar a importância relativa dos agricultores familiares pobres potencialmente enquadráveis no Grupo B do Pronaf e verificar sua distribuição socioespacial no Rio Grande do Norte (RN), estado nordestino que se destaca nacionalmente por apresentar a maior proporção de seu território na área do semiárido brasileiro. Além disso, pretende-se analisar as condições de reprodução econômica desses produtores a partir das "tabulações especiais" das estatísticas censitárias mencionadas anteriormente, objetivando compreender os fatores que bloqueiam sua capacidade de gerar renda agropecuária e suas principais fontes de receitas monetárias.

É importante mencionar que, no RN, ainda se tem pouco conhecimento acumulado sobre a real dimensão e o perfil social do Grupo B. Isto porque os estudos realizados sobre o tema nesta unidade federativa ou se limitaram a avaliar a distribuição do crédito do Pronaf por meio de dados secundários, ou se restringiram a pesquisas de campo municipais elaboradas a partir de 
S170 - Magnitude e Condições de Reprodução Econômica dos Agricultores Familiares Pobres no Semiárido Brasileiro: evidências a partir do Rio Grande do Norte

amostras limitadas do público que efetivamente recebeu o microcrédito do Pronaf (BASTOS, 2006; GOMES DA SILVA et al., 2007; HOLANDA, 2010; MAIA, 2008). Nesse sentido, a investigação proposta, ao abarcar todo o universo de produtores pobres identificados pelo Censo de 2006, pode ajudar a avançar nos estudos sobre essa categoria específica de produtores no meio rural potiguar.

A estrutura do texto está divida em mais três seções, além desta introdução. A próxima seção descreve de forma didática a metodologia utilizada pelo IBGE para delimitar os agricultores familiares e identificar os produtores mais pobres nas estatísticas censitárias. A terceira seção apresenta os resultados e discute os indicadores compilados por intermédio da pesquisa empreendida. Ao final, na quarta seção, com base nesses resultados, são feitas algumas considerações gerais sobre o tema abordado, bem como seus desdobramentos para a realização de novas investigações.

\section{Metodologia}

\subsection{Delimitação da agricultura familiar e não familiar no Censo Agropecuário 2006}

Os dados utilizados para fundamentar a análise proposta no presente artigo são provenientes do Censo Agropecuário realizado pelo IBGE em 2007, cuja data de referência foi 31 de dezembro de 2006. Todavia, é pertinente esclarecer que eles apresentam um caráter particular em relação a outros indicadores similares disponíveis nos sítios eletrônicos oficiais até recentemente, pois foram obtidos a partir de "tabulações especiais" da segunda apuração das estatísticas censitárias disponibilizadas para consulta pública no Sistema IBGE de Recuperação Automática de Dados (Sidra) apenas em 2012.

4. As "tabulações especiais" às quais se faz referência são resultado do tratamento diferenciado das estatísticas censitárias realizado pelos técnicos do IBGE e do Ministério do Desenvolvimento Agrário (MDA). A partir delas, pela primeira vez na história, o IBGE conseguiu gerar informações sobre o universo de agricultores familiares e o público potencial do Pronaf no Brasil. Tais informações,
Conforme explica o próprio IBGE (2012), com a intensificação do uso das informações da primeira apuração do Censo 2006, divulgadas em 2009, foram detectadas pelos usuários algumas divergências com relação aos dados das pesquisas agropecuárias contínuas. Assim sendo, se fez necessário proceder à revisão completa dos indicadores questionados, promovendo uma reavaliação dos procedimentos de geração de todas as variáveis, culminando na elaboração da nova base de dados referenciada, que substitui integralmente os números da primeira apuração.

O processo de elaboração das "tabulações especiais", de forma específica, envolveu um conjunto de etapas sucessivas e complementares entre si. De posse dos dados primários da segunda apuração do Censo Agropecuário 2006, os técnicos do IBGE e do Ministério do Desenvolvimento Agrário (MDA) realizaram, inicialmente, a separação dos estabelecimentos recenseados em "Familiares" e "Não Familiares". Nessa fase, recorreu-se inteiramente à metodologia inovadora desenvolvida pela parceria entre as instituições citadas, que delimitou o universo familiar no Brasil por meio da aplicação dos critérios da Lei n. 11.326/2006 - mais conhecida como a Lei da Agricultura Familiar.

Desse modo, com base nos critérios da mencionada lei, foram considerados "Familiares" todos os produtores que (DEL GROSSI e MARQUES, 2010; IBGE, 2009; IBGE/SIDRA, 2012):

1. não detivessem estabelecimentos com área maior que quatro módulos fiscais;

2. utilizassem predominantemente a mão de obra da própria família nas atividades do seu estabelecimento ou empreendimento;

3. tivessem a renda familiar predominantemente originada de atividades vinculadas ao próprio estabelecimento; e

4. dirigissem o estabelecimento em conjunto com sua família.

acessíveis até pouco tempo apenas por meio de solicitação oficial, foram disponibilizadas para consulta pública no site da instituição no final do segundo semestre de 2012 (AQUINO et al., 2011, 2014; IBGE/SIDRA, 2012). 
Por exclusão, os estabelecimentos não enquadrados simultaneamente nos critérios descritos foram classificados como não familiares. Em outros termos, eram estabelecimentos com mais de quatro módulos fiscais, tocados predominantemente por trabalhadores assalariados e dirigidos por administradores ou capatazes. Nessa perspectiva, em sintonia com estudos anteriores (FAO/INCRA, 2000; KAGEYAMA, BERGAMASCO e OLIVEIRA, 2013), os estabelecimentos foram definidos não por sua área/tamanho, mas por suas relações sociais de produção, se familiares ou do tipo patrão-empregado.

Deve-se registrar que o recorte empregado em nenhum momento buscou atribuir qualquer juízo de valor aos segmentos identificados. A ideia básica foi, fundamentalmente, agrupar os produtores com características socioeconômicas semelhantes a partir dos fundamentos legais adotados no País. Ao seguir esse procedimento, foi possível ir além dos estudos focados apenas na extensão territorial das propriedades rurais.

É pertinente sublinhar, ainda, que o trabalho coletivo do IBGE/MDA não se resumiu apenas a delimitar os agricultores familiares no Brasil. Posteriormente à apuração dos primeiros resultados do recenseamento, também foi realizado um esforço paralelo no sentido de captar as diferenças internas do segmento, usando a legislação vigente na distribuição do crédito rural do Pronaf como parâmetro de estratificação.

\subsection{Classificação dos agricultores familiares pobres do Grupo B a partir das normas do Pronaf 2006/2007}

Após a identificação dos agricultores familiares, o passo seguinte na construção das "tabulações especiais" foi extrair das estatísticas do Censo Agropecuário 2006 o conjunto formado pelos estabelecimentos que se enquadravam nas normas oficiais da política de crédito do Pronaf, ou seja, o público potencial do programa. Tal procedimento viabilizou-se através de outra inovação do banco de dados criado pela parceria do IBGE com o MDA, que permitiu a inserção de variáveis derivadas nos dados censitários, possibilitando tipificar os produtores familiares em "pronafianos" (Familiares Pronaf) e "não pronafianos" (Familiares não Pronaf).

Assim sendo, adotando as normas operacionais do crédito rural vigentes no Plano Safra 2006/2007 como parâmetro, foram considerados "pronafianos" apenas os estabelecimentos enquadrados na Lei n. 11.326 que: obtivessem rendimentos anuais até $R \$ 80$ mil e usassem predominantemente o trabalho da família ou, no máximo, dois empregados permanentes. Tipificados os grupos de "pronafianos", os demais estabelecimentos familiares, com rendimentos acima de $\mathrm{R} \$ 80$ mil e com mais de dois empregados permanentes, foram considerados "não pronafianos" (Familiares não Pronaf).

Os estabelecimentos familiares "pronafinos", por seu turno, foram estratificados nos cinco grupos que formavam o público potencial do Pronaf em $2006^{5}$. Entre eles, foram caracterizados como Grupo B todos aqueles agricultores que atendessem às seguintes condições (DEL GROSSI, 2011; IBGE/SIDRA, 2012; MDA/SAF/PRONAF, 2006):

1. explorassem parcela de terra na condição de proprietário, posseiro, arrendatário ou parceiro;

2. residissem na propriedade ou em local próximo;

3. não dispusessem, a qualquer título, de área de terra superior a 4 (quatro) módulos fiscais quantificados segundo a legislação em vigor;

4. obtivessem, no mínimo, 30\% (trinta por cento) da renda familiar da exploração agropecuária e não agropecuária do estabelecimento;

5. De 2000 a 2008, o público potencial do Pronaf era composto pelos grupos "A" (assentados), "B" (pobres), "C" (intermediários), "D" e "E" (consolidados). Cada um deles, de acordo com o seu nível de renda, recebia um tratamento diferenciado no momento da concessão do crédito ofertado em condições especiais. A partir da safra 2008/2009, as regras do programa foram alteradas e os estratos " $\mathrm{C}$ ", " $\mathrm{D}$ " e "E" foram agregados em um único grupo denominado de "agricultores familiares" ou, simplesmente, de "Grupo Variável" (MATTEI, 2008). 
S172 - Magnitude e Condições de Reprodução Econômica dos Agricultores Familiares Pobres no Semiárido Brasileiro: evidências a partir do Rio Grande do Norte

Quadro 1. Segmentação dos estabelecimentos agropecuários a partir da Lei da Agricultura Familiar e das normas do Pronaf vigentes na safra 2006/2007

\begin{tabular}{|l|l|l|}
\hline \multirow{2}{*}{ Estabelecimentos agropecuários - Censo Agropecuário 2006 } & \multicolumn{2}{|c|}{ Não Familiar } \\
\cline { 3 - 3 } & \multirow{2}{*}{ Familiar - Lei n. 11.326 } & Familiar (Grupo B) \\
\cline { 3 - 3 } & & Familiar (exceto Grupo B) \\
\hline
\end{tabular}

Fonte: Elaboração dos autores.

5. tivessem o trabalho familiar como base na exploração do estabelecimento e não detivessem empregados permanentes; e

6. obtivessem renda bruta anual familiar com rebate ${ }^{6}$ - de até $\mathrm{R} \$ 3.000,00$ (três mil reais).

A aplicação simultânea de cada um desses critérios de classificação resultou na identificação de dois segmentos distintos de agricultores familiares: o primeiro, formado pelos produtores mais pobres que são objeto deste estudo, abrangendo todos os estabelecimentos recenseados com renda bruta anual familiar "rebatida" igual ou inferior a R\$ 3 mil (Familiar [Grupo B]); e o segundo, constituído pelos assentados da reforma agrária e outros agricultores familiares "pronafianos" e "não pronafianos" com renda superior a R 3 mil por ano (Familiar [exceto Grupo B]).

Os parâmetros de estratificação detalhados nos parágrafos anteriores permitiram aos técnicos do IBGE e do MDA, finalmente, gerar informações individualizadas referentes ao segmento de agricultores familiares pobres presente na estrutura agrária brasileira e do Rio Grande do Norte. A partir daí foram usadas técnicas estatísticas para realizar o cruzamento das variáveis

6. Define-se renda bruta anual familiar como sendo aquela proveniente de atividades agropecuárias e não agropecuárias desenvolvidas no interior do estabelecimento e/ou fora dele por qualquer membro da família. No seu cálculo, contabilizam-se $100 \%$ das rendas não rurais, excluídos o valor dos benefícios sociais e os proventos previdenciários decorrentes das atividades rurais. Além disso, para efeito de enquadramento dos grupos de "pronafianos" ("B", "C", "D" e "E"), a norma do Conselho Monetário Nacional $(\mathrm{CMN})$ que regulava as operações de crédito na safra 2006/2007 ainda determinava que a renda bruta familiar devia ser "rebatida" em algumas atividades específicas, ou seja, ter descontos, aproximando-se, assim, da renda líquida do empreendimento (DEL GROSSI, 2011). da segunda apuração do Censo Agropecuário 2006 e, com isso, gerar o banco de dados sobre as condições de reprodução social dessa categoria específica de produtores. A síntese resultante dos critérios adotados pode ser visualizada no Quadro 1, que indica ser possível aprofundar o entendimento da diversidade que existe na agropecuária brasileira e norte-rio-grandense por meio das "tabulações especiais" que foram construídas a partir dos dados censitários disponíveis no Sidra (http://www.sidra.ibge.gov.br/).

Os novos números obtidos através dos procedimentos destacados foram rigorosamente corrigidos e vários indicadores foram atualizados em relação à publicação original do IBGE (2009), representando um "passo adiante" na parceria interinstitucional deste órgão com o MDA (DEL GROSSI, 2011; IBGE/SIDRA, 2012). A partir deles, é possível avançar na compreensão da heterogeneidade e pobreza que marca o meio rural do RN no limiar do século XXI, em que os agricultores familiares pobres se destacam como categoria predominante mesmo em um ano em que as chuvas foram regulares na maior parte do estado.

\section{Resultados e discussão}

A apresentação dos resultados será feita em cinco subseções. Na primeira, são apresentados os indicadores referentes à distribuição socioespacial dos agricultores do Grupo B no espaço geográfico potiguar. Já as subseções seguintes são dedicadas à análise do perfil e das condições de reprodução econômica deste segmento específico de produtores rurais, que engloba os mais pobres entre os agricultores familiares mapeados pelo IBGE, em 2006. 


\subsection{Magnitude e distribuição socioespacial do público potencial do Pronaf B no Rio Grande do Norte}

O Rio Grande do Norte (RN) ocupa uma área territorial de $52.811 \mathrm{~km}^{2}$ dividida politicamente entre 167 municípios, agrupados em quatro mesorregiões (Oeste Potiguar, Central Potiguar, Agreste Potiguar e Leste Potiguar) e em 19 microrregiões geográficas (BNB, 2013). Entre os estados nordestinos, trata-se daquele em que os produtores rurais estão mais vulneráveis às irregularidades climáticas que caracterizam a região, já que 93\% do seu território está inserido no espaço geográfico do semiárido brasileiro, onde "as chuvas são irregulares ou, quando normais, as médias de precipitação são baixas, tornando a água um bem natural escasso" (FELIPE, CARVALHO e ROCHA, 2006, p. 63).

Os dados das "tabulações especiais" da segunda apuração do Censo Agropecuário, apresentados na Tabela 1, revelaram que existiam 83.053 estabelecimentos agropecuários no RN em 2006. Deste total, 71.210 eram constituídos por produtores familiares enquadrados nos critérios da Lei n. 11.326, representando o percentual expressivo de $85,74 \%$ dos estabelecimentos recenseados no período. Por conseguinte, o segmento não familiar era composto por 11.843 produtores, o que correspondia a $14,26 \%$ do total de unidades de produção agropecuárias do estado.
O grupo de produtores mais representativo na agropecuária potiguar, entretanto, era composto pelo segmento de "pronafianos" com renda bruta anual inferior a R\$ 3 mil. Como pode ser visualizado na tabela em foco, os agricultores familiares enquadráveis no Pronaf $B$ eram representados por 42.234 estabelecimentos, que englobavam $50,85 \%$ do total das unidades de produção agropecuárias norte-rio-grandenses. Cumpre ressaltar que o referido segmento era numericamente superior ao subconjunto formado pelos assentados da reforma agrária e demais tipos de agricultores familiares (Familiar [exceto Grupo B]), que representavam 34,89\% (pouco mais de $1 / 3$ ) dos 83 mil estabelecimentos agrícolas existentes no meio rural do estado na data de referência do Censo do IBGE.

Tais informações comprovam, em princípio, que há uma forte presença de produtores pobres no espaço agrário do RN. Logo, a agricultura familiar de subsistência - "reconhecida pelo fato de não gerar excedentes de renda monetária, ou fazê-lo em proporções reduzidas" (DELGADO, 2005, p. 40) - ainda é predominante no rural potiguar, apesar da expansão recente de políticas agrícolas como o Pronaf, da criação de assentamentos de reforma agrária e das transformações verificadas na estrutura produtiva do setor agropecuário estadual, destacando-se o avanço do agronegócio no polo de irrigação Açu-Mossoró, que se cons-

Tabela 1. Segmentação da estrutura da agropecuária do Rio Grande do Norte e participação do Grupo B do Pronaf no total de estabelecimentos - 2006

\begin{tabular}{lcc}
\hline \multicolumn{1}{c}{ Tipos de Agricultura } & № de Estabelecimentos & $\%$ \\
\hline Não Familiar & 11.843 & 14,26 \\
Familiar - Lei n. 11.326 & 71.210 & 85,74 \\
$\quad$ Familiar (Grupo B) & 42.234 & 50,85 \\
$\quad$ Familiar (exceto Grupo B) & 28.976 & 34,89 \\
Total Geral & $\mathbf{8 3 . 0 5 3}$ & $\mathbf{1 0 0 , 0 0}$ \\
\hline
\end{tabular}

Nota: Dados organizados pelos autores.

Fonte: Tabulação especial da segunda apuração do Censo Agropecuário 2006 (IBGE/SIDRA, 2012). 
S174 - Magnitude e Condições de Reprodução Econômica dos Agricultores Familiares Pobres no Semiárido Brasileiro: evidências a partir do Rio Grande do Norte

Tabela 2. Participação relativa dos estabelecimentos do Grupo B do Pronaf no interior da agricultura familiar por microrregiões do Rio Grande do Norte - 2006

\begin{tabular}{lccc}
\hline \multicolumn{1}{c}{ Microrregióes } & $\begin{array}{c}\text { Familiar } \text { - Lei n. 11.326 } \\
\text { (a) }\end{array}$ & $\begin{array}{c}\text { Grupo B } \\
\text { (b) }\end{array}$ & $\begin{array}{c}\% \\
\text { (b/a) }\end{array}$ \\
\hline Agreste Potiguar & 11.907 & 8.599 & 72,22 \\
Angicos & 2.463 & 987 & 40,07 \\
Baixa Verde & 2.021 & 749 & 37,06 \\
Borborema Potiguar & 7.658 & 5.388 & 70,35 \\
Chapada do Apodi & 5.426 & 2.769 & 51,03 \\
Litoral Nordeste & 3.777 & 1.738 & 46,01 \\
Litoral Sul & 1.818 & 1.423 & 78,27 \\
Macaíba & 2.683 & 1.082 & 40,32 \\
Macau & 715 & 254 & 35,52 \\
Médio Oeste & 1.809 & 879 & 48,59 \\
Mossoró & 3.486 & 30,26 \\
Natal & 271 & 1.055 & 66,78 \\
Pau dos Ferros & 4.710 & 181 & 69,15 \\
Seridó Ocidental & 1.580 & 3.257 & 55,95 \\
Seridó Oriental & 3.031 & 884 & 57,87 \\
Serra de Santana & 5.979 & 1754 & 58,54 \\
Serra de São Miguel & 5.100 & 3.500 & 79,27 \\
Umarizal & 3.276 & 4.043 & 70,73 \\
Vale do Açu & 3.500 & 2.317 & 39,28 \\
Total RN & 71.210 & 1.375 & 59,31 \\
\hline
\end{tabular}

Nota: Dados organizados pelos autores.

Fonte: Tabulação especial da segunda apuração do Censo Agropecuário 2006 (IBGE/SIDRA, 2012).

titui numa das principais áreas de produção de frutas frescas para exportação do Nordeste ${ }^{7}$.

Do ponto de vista da distribuição socioespacial, os produtores pobres estão dispersos em praticamente todo o território potiguar e abrangem a parcela majoritária dos agricultores familiares abrigados neste espaço $(59,31 \% \text { do total })^{8}$.

7. A partir da década de 1990, alguns setores da agropecuária potiguar passaram por um significativo processo de modernização e reestruturação produtiva. De acordo com Pereira Jr. e Matos Filho (2009), entre esses setores se destacam: a fruticultura irrigada, a carcinicultura, a apicultura, a bovinocultura leiteira e a caprinocultura. $O$ referido processo de modernização, entretanto, tem sido marcado pela desigualdade de oportunidades e pelo aumento da dependência e vulnerabilidade dos produtores familiares. Para uma análise desse e outros aspectos na área da fruticultura norte-rio-grandense, ver Nunes e Schneider (2012).

8. Mesmo diante da precariedade da situação retratada, deve-se assinalar que o RN é o estado nordestino que apresenta o menor percentual de agricultores familiares pobres entre os familiares (AQUINO et al., 2011, 2014). Isso mostra uma situação mais confortável nas terras potiguares, mas não é motivo para qualquer ufanismo, já que o drama da pobreza extrema alcança aproximadamente $60 \%$ dos agricultores familiares.
Esse aspecto pode ser observado na Tabela 2, que mostra de forma panorâmica a magnitude relativa do Grupo B em relação ao universo de agricultores familiares nas 19 microrregiões geográficas do estado. Entre elas, as que apresentaram a mais forte participação de produtores de baixa renda no interior da agricultura familiar foram: Serra de São Miguel $(79,27 \%)$, Litoral Sul $(78,27 \%)$, Agreste Potiguar $(72,22 \%)$, Umarizal $(70,73 \%)$ e Borborema Potiguar $(70,35 \%)$. Essas cinco microrregiões abrigavam $51,45 \%$ do total de estabelecimentos familiares do Grupo B (21.730). As microrregiões de Mossoró e do Vale do Açu, consideradas as mais dinâmicas do RN por conta das atividades ligadas à fruticultura irrigada, registram baixos percentuais relativos de produtores pobres, com $30,26 \%$ e $39,28 \%$ dos seus agricultores familiares enquadráveis no Grupo B, respectivamente.

Ainda conforme os números da Tabela 2, vale destacar que em 11 das microrregiões analisadas (58\% do total) a participação dos produtores do 
Grupo B superava a marca de $50 \%$ dos agricultores familiares recenseados, evidenciando, por este ângulo, mais uma vez, o alto grau de pobreza prevalecente na agropecuária do $\mathrm{RN}$, mesmo considerando o fato de que a média estadual $(59,31 \%)$ ficou bem abaixo da média nordestina (72\%), como evidenciaram as análises comparativas realizadas por Aquino et al. $(2011,2014)$.

Em suma, as informações apresentados nesta subseção indicaram quantos são e onde estão os agricultores familiares pobres no RN. Por sua representatividade numérica, os agricultores do Grupo B representam a categoria de produtores mais expressiva na estrutura agrária potiguar. Depois de desvelar esse aspecto social, geralmente escondido pela expressão genérica "agricultura familiar", é preciso avançar na investigação e procurar evidenciar alguns traços marcantes que determinam as condições de reprodução econômica desse segmento particular de produtores. Para isso, recorrer-se-á, nas próximas subseções, às "novidades" do Censo Agropecuário 2006, que, além dos indicadores tradicionais de área, produção e produtividade agrícolas, incluiu no levantamento variáveis socioeconômicas tais como: escolaridade e qualificação profissional, nível de organização dos produtores, rendas não agrícolas etc. Essas novidades, conforme Kageyama, Bergamasco e Oliveira (2008), ampliam as possibilidades de pesquisa ao permitir retratar características da agricultura familiar até então pouco estudadas em sua magnitude.

\subsection{Perfil dos chefes dos estabelecimentos familiares pobres}

Os 42.234 estabelecimentos familiares enquadráveis no Grupo B do Pronaf localizados no RN eram dirigidos, em sua maioria, por homens de idade avançada. De acordo com os dados apurados pelo IBGE/Sidra (2012), do total de propriedades identificadas pelo Censo de 2006, uma pequena parte era gerida por jovens com menos de 25 anos (3,40\%), percentual inferior à média da região Nordeste. Além disso, observa-se que $31 \%$ dos responsáveis pelos estabelecimentos de baixa renda encontrava-se na faixa etária de 25 a 45 anos; $40,31 \%$ pertenciam à faixa de 45 a 65 anos, e pelo menos $1 / 4$ estava no grupo dos idosos, com 65 anos ou mais.

Outro aspecto revelado pelo Censo Agropecuário 2006 refere-se ao fato de que, para os agricultores familiares pobres norte-rio-grandenses, o meio rural representa mais do que um espaço de produção, se constituindo também em um local de moradia. Um prova disso é que, entre os chefes dos estabelecimentos entrevistados, 76,67\% declararam que residiam no próprio estabelecimento. Afora esses, 11,33\% informaram residir na zona rural, mas fora do estabelecimento, e $12 \%$ moravam em áreas urbanas localizadas nas proximidades do sítio. Ao todo, nada menos do que $88 \%$ dos produtores trabalhavam e viviam no campo (IBGE/SIDRA, 2012).

No tocante ao nível educacional dos chefes dos estabelecimentos familiares do Grupo B no $\mathrm{RN}$, chama atenção a precariedade dos indicadores encontrados no levantamento de campo realizado pelos pesquisadores do IBGE. Assim, segundo os dados da Tabela 3, dos 42.234 dirigentes dos estabelecimentos com rendimentos anuais inferiores a $\mathrm{R} \$ 3$ mil encontrados no meio rural potiguar em 2006, 45,43\% não sabiam ler e nem escrever; 8,70\% disseram apenas ler e escrever; $35,44 \%$ possuíam o ensino fundamental incompleto e apenas 10,43\% declararam ter avançado além desse nível de estudo ou possuir alguma qualificação profissional.

Deve-se admitir que a baixa escolaridade não pode ser atribuída exclusivamente ao público de potenciais clientes do microcrédito do Pronaf B. Contudo, pela dramaticidade do quadro retratado no RN e no Nordeste, não há como ignorar o fato de que a carência de instrução formal pode ser um dos fatores explicativos do estado de pobreza que caracteriza esse grupo particular de agricul- 
S176 - Magnitude e Condições de Reprodução Econômica dos Agricultores Familiares Pobres no Semiárido Brasileiro: evidências a partir do Rio Grande do Norte

Tabela 3. Nível de instrução da pessoa que dirige os estabelecimentos familiares do Grupo B do Pronaf no Rio Grande do Norte - 2006

\begin{tabular}{lcc}
\hline \multicolumn{1}{c}{ Nível de instrução } & No de agricultores & $\%$ \\
\hline Não sabe ler e escrever & 19.188 & 45,43 \\
Nenhum nível de instrução (apenas sabe ler e escrever) & 3.678 & 8,70 \\
EJA e Ensino Fundamental incompleto & 14.966 & 35,44 \\
Ensino Fundamental completo & 2.270 & 5,38 \\
Outros* & 2.132 & 5,05 \\
Total Grupo B & 42.234 & 100,00 \\
\hline
\end{tabular}

* Na categoria "Outros" foram incluídos os entrevistados que declararam ter graus de formação variados (Ensino Médio Completo, Técnico Agrícola Completo, Graduação em Engenharia Agronômica, Veterinária, Zootecnia, Engenharia Florestal ou outra formação superior).

Fonte: Tabulação especial da segunda apuração do Censo Agropecuário 2006 (IBGE/SIDRA, 2012).

tores familiares, o que corrobora a tese de que a baixa escolarização pode significar baixa renda monetária9.

Além dos baixos níveis educacionais, outro fator desfavorável ao grupo de produtores pobres referia-se ao seu baixo nível de participação em organizações sociais coletivas. Dos chefes dos estabelecimentos do Grupo B norte-rio-grandenses, apenas 40,14\% eram vinculados a alguma entidade de classe - a exemplo de sindicatos e associações comunitárias rurais (IBGE/SIDRA, 2012). Quanto à participação em cooperativas, a situação se apresentava ainda mais precária, pois somente $2,30 \%$ dos agricultores pobres declararam fazer parte desse tipo de agremiação, o que evidencia a situação de isolamento em que desenvolvem suas atividades produtivas e comercializam os resultados da produção.

Em linhas gerais, os dados censitários informaram que os estabelecimentos do Grupo B potiguares são dirigidos predominantemente por homens de idade avançada residentes no campo,

9. A literatura especializada aponta que, ao lado da desigualdade na distribuição da posse da terra, o baixo nível de capital humano é um dos principais fatores explicativos da precariedade das condições de reprodução social de parcela expressiva da população rural brasileira, especialmente nos estados nordestinos. Conforme explicam Ney e Hoffmann (2009, p. 155), amparados em uma rigorosa análise dos dados estatísticos apurados pelos censos demográficos do IBGE, as famílias rurais pobres brasileiras são vitimadas pela "escassez de dois ativos fundamentais na determinação da renda nas áreas onde vivem: terra para plantar e educação, variável que, em qualquer setor de atividade, influencia de forma significativa os níveis de produtividade e renda do trabalho". com baixos níveis de escolaridade e pouca participação em entidades de classe e cooperativas. Esses fatores individuais, somados à escassez de recursos naturais e à baixa utilização de tecnologias necessárias à melhoria da produtividade dos estabelecimentos, podem ser variáveis explicativas do grau de pobreza que caracteriza tais produtores. É o que se procurará mostrar na sequência do presente estudo.

\subsection{Acesso dos estabelecimentos do Grupo B a base de recursos naturais}

No Rio Grande do Norte (RN), à semelhança dos demais estados brasileiros, verifica-se elevada desigualdade na distribuição da posse da terra (HOFFMANN e NEY, 2010). Essa realidade se torna visível quando se compara o tamanho médio das propriedades dos produtores familiares e não familiares no rural potiguar a partir da Figura 1. Nele, fica claro que estes últimos apresentam área média de 180,85 ha, o que corresponde a oito vezes o tamanho da área produtiva familiar e aproximadamente 18 vezes mais do que a área pertencente ao grupo de agricultores pobres, com rendimentos "rebatidos" até R\$ 3 mil por ano.

Os produtores familiares potiguares dispõem, em geral, de pouca terra para produzir, mas a situação do Grupo B é a mais precária. Como é possível observar no mesmo gráfico já mencionado no parágrafo anterior, a área média dos assentados e demais estabelecimentos familiares com renda 
Figura 1. Área média dos estabelecimentos agropecuários do Rio Grande do Norte - 2006 (Em hectares)

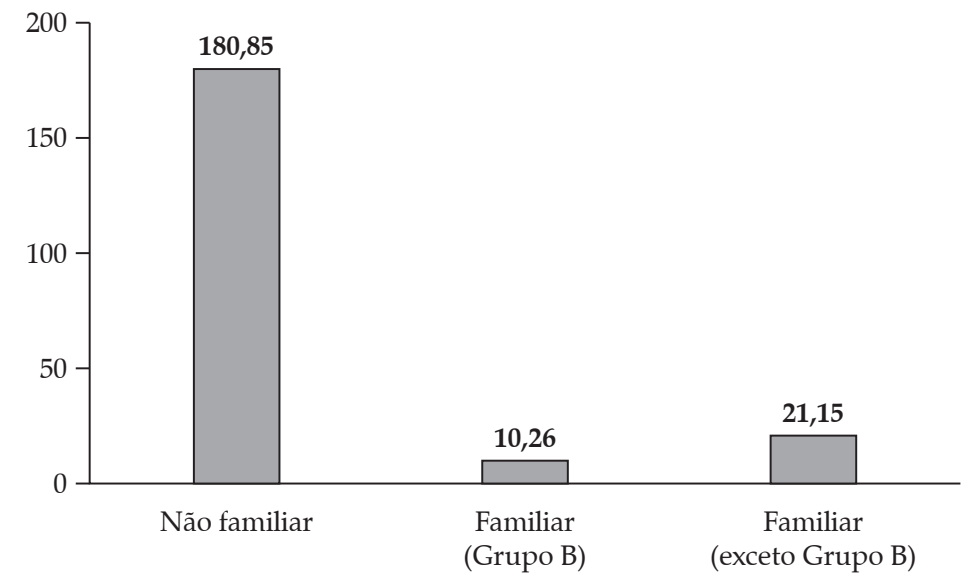

Nota: Dados organizados pelos autores.

Fonte: Tabulação especial da segunda apuração do Censo Agropecuário 2006 (IBGE/SIDRA, 2012).

acima de R\$ 3 mil era de 21,15 ha, ou seja, praticamente o dobro do tamanho das propriedades dos agricultores familiares pobres, cujas áreas médias eram de apenas 10,26 ha.

A Tabela 4, por seu turno, apresenta a estratificação dos estabelecimentos familiares do Pronaf B por grupos de área total, indicando que a situação de restrição fundiária é mais grave do que o cálculo da média demonstra. Isso porque, no RN, a maioria dos produtores estudados $(54,54 \%)$ tem menos de cinco hectares de terra para trabalhar e viver. Ademais, aproximadamente $8 \%$ estavam enquadrados na categoria produtor sem área, $12,52 \%$ tinham áreas inferiores a 10 ha e apenas cerca de 1/4 dos estabelecimentos dispunha de extensões de terra acima do patamar médio estadual. Já em termos de percentual acumulado, constata-se que $67,06 \%$ dos estabelecimentos do Grupo B possuíam áreas iguais ou inferiores a 10 hectares.

Os dados expostos até aqui sinalizam que a restrição fundiária é uma das variáveis que se correlacionam com o nível de pobreza da maior parte dos agricultores familiares norte-rio-grandenses. Dessa forma, além das limitações climáticas impostas pela localização geográfica onde os estabelecimentos estão inseridos (zona semiárida), tudo indica que a reduzida quantidade de terra disponível é um dos principais fatores que restringe as possibilidades de os produtores

Tabela 4. Estratificação por grupos de área total dos estabelecimentos familiares do Grupo B do Pronaf no Rio Grande do Norte - 2006

\begin{tabular}{lccc}
\hline \multicolumn{1}{c}{ Estrato de área (em hectares) } & No de Estabelecimentos & $\%$ & \% Acumulado \\
\hline $0-5$ & 23.032 & 54,54 & 54,54 \\
$5-10$ & 5.290 & 12,52 & 67,06 \\
$10-50$ & 8.246 & 19,53 & 86,59 \\
$50-100$ & 1.836 & 4,35 & 90,94 \\
Mais de 100 & 501 & 1,18 & 92,12 \\
Produtor sem área & 3.329 & 7,88 & 100,00 \\
Total Grupo B & $\mathbf{4 2 . 2 3 4}$ & $\mathbf{1 0 0 , 0 0}$ & - \\
\hline
\end{tabular}

Nota: Dados organizados pelos autores.

Fonte: Tabulação especial da segunda apuração do Censo Agropecuário 2006 (IBGE/SIDRA, 2012). 
S178 - Magnitude e Condições de Reprodução Econômica dos Agricultores Familiares Pobres no Semiárido Brasileiro: evidências a partir do Rio Grande do Norte

Tabela 5. Fontes de água existentes no interior dos estabelecimentos familiares do Grupo B do Pronaf no Rio Grande do Norte - 2006 (Em \%)

\begin{tabular}{lc}
\hline \multicolumn{1}{c}{ Tipos de fontes de água disponíveis } & $\%$ de acesso \\
\hline Poços comuns & 10,30 \\
Cisternas & 33,04 \\
Poços artesianos ou semiartesianos & 3,74 \\
\hline
\end{tabular}

Nota: Dados organizados pelos autores.

Fonte: Tabulação especial da segunda apuração do Censo Agropecuário 2006 (IBGE/SIDRA, 2012).

garantirem a sua sobrevivência a partir da exploração de atividades agropecuárias ${ }^{10}$.

Em adição à escassez relativa de terra, a Tabela 5 indica que a falta de fontes de armazenamento de água também é outro problema grave enfrentado pelos agricultores familiares do Grupo B. Isto porque, do total pesquisado, somente $10,30 \%$ disseram possuir poços comuns em suas propriedades; $33,04 \%$ possuíam cisternas e apenas $3,74 \%$ contavam com poços artesianos ou semiartesianos. É importante enfatizar que, apesar da precariedade dos percentuais em tela, a situação hídrica do RN é relativamente melhor que a média regional, uma vez que tão somente $18,27 \%$ dos estabelecimentos agropecuários nordestinos possuíam cisternas como forma de garantir o abastecimento mínimo de água das famílias, em 2006.

Independentemente da pequena vantagem que ostenta em relação à média regional, o Censo do IBGE revela que uma parcela majoritária dos produtores do Grupo B norte-rio-grandenses não tinha acesso a fontes de água em seus estabelecimentos. Ou seja, eles estavam vulneráveis à escassez hídrica que caracteriza o semiárido em virtude

10. Há muitas evidências que mostram que a falta de terra é um importante fator para explicar as diferenças de pobreza entre os produtores agrícolas brasileiros. Segundo os testes econométricos realizados por Helfand, Moreira e Figueiredo (2011, p. 409), por exemplo, "se os produtores do NE [Nordeste] tivessem a distribuição da terra dos produtores de qualquer outra região, a pobreza cairia entre 31 pp e 51 pp. Este resultado está de acordo com a visão de que os produtores pobres muitas vezes possuem áreas de tamanho insuficiente para saírem da pobreza." Os referidos autores alertam, porém, que é improvável que uma política de redistribuição dos ativos fundiários, isoladamente, seja capaz de elevar a renda agrícola no campo, necessitando ser integrada com outras ações governamentais capazes de melhorar a produtividade dos estabelecimentos agropecuários. das secas que se repetem periodicamente no território estadual (FELIPE, CARVALHO e ROCHA, 2006; MAIA GOMES, 2001; NEVES, MELO e SAMPAIO, 2011). Portanto, ao enfrentarem longos períodos de estiagem, eles são susceptíveis ao risco de piorar ainda mais sua situação social por falta de condições mínimas de produção.

Depreende-se, então, que o acesso precário à terra e a baixa disponibilidade de fontes perenes de armazenamento de água nas pequenas propriedades representam um grande entrave para o desenvolvimento dos agricultores familiares pesquisados. No entanto, como será apresentado na próxima subseção, esse cenário se torna mais grave ao se considerar a pouca qualificação da mão de obra empregada e as precárias condições tecnológicas destes produtores.

\subsection{Mão de obra ocupada e características tecnológicas dos estabelecimentos do Grupo B}

Os estabelecimentos do Grupo B do Pronaf se constituem no principal reservatório de mão de obra presente nas áreas rurais norte-rio-grandenses. Com base nos dados compilados das "tabulações especiais" da segunda apuração do Censo Agropecuário 2006 (IBGE/SIDRA, 2012), 102.389 pessoas estavam ocupadas nas pequenas propriedades deste tipo de produtor, o que correspondia a $41,37 \%$ da mão de obra ocupada na agropecuária potiguar na data de referência da pesquisa. Os estabelecimentos não familiares, embora detivessem as maiores áreas médias de terra, respondiam apenas por $22,61 \%$ da mão de obra ocupada, número inferior ao verificado nos demais estabelecimentos familiares, que man- 
Tabela 6. Características tecnológicas dos estabelecimentos familiares do Grupo B do Pronaf no Rio Grande do Norte 2006 (Em \%)

\begin{tabular}{lc}
\hline \multicolumn{1}{c}{ Variáveis } & $\%$ \\
\hline Uso de força de tração animal & 47,18 \\
Uso de força de tração mecânica & 26,83 \\
Faz pousio ou descanso de solo & 11,70 \\
Uso de adubos em lavouras & 9,99 \\
Faz irrigação & 3,69 \\
Tem silos de armazenar forragem & 0,73 \\
\hline
\end{tabular}

Nota: Dados organizados pelos autores.

Fonte: Tabulação especial da segunda apuração do Censo Agropecuário 2006 (IBGE/SIDRA, 2012).

tinham $36 \%$ da população ocupada na data de referência do recenseamento do IBGE.

As referidas "tabulações especiais" mostram ainda que as pessoas ocupadas nos estabelecimentos do Grupo B eram predominantemente da família do produtor e apresentavam baixíssimo nível educacional. De forma conjunta, 93,33\% da população ocupada nestes estabelecimentos eram ligados ao produtor por algum laço de parentesco. Destes, 51,52\% eram analfabetos (não sabiam ler ou escrever), indicando que a precariedade do quadro educacional não abrange apenas a maioria absoluta dos chefes das unidades de produção, como foi visto na subseção 3.1, mas também os demais membros de suas famílias.

Com efeito, afora os baixos níveis de capital humano, a Tabela 6 evidencia que o padrão tecnológico prevalecente no âmbito da agricultura familiar de subsistência potiguar também era extremamente baixo. Em relação ao tipo de força de tração utilizada nas pequenas propriedades, $47,18 \%$ dos produtores do RN faziam uso de tração animal e apenas $26,83 \%$ utilizavam a tração mecânica. Isso significa que o grosso das atividades era exercido de forma manual, ou seja, no "braço e na enxada", demonstrando a penosidade das condições de trabalho que, nas temperaturas elevadas que caracterizam o clima do semiárido brasileiro, debilitam anualmente a capacidade física da população ocupada cotidianamente nos estabelecimentos "pronafianos" de baixa renda.

Além de não contarem com o auxílio de força complementar ao trabalho humano, seja animal ou mecânica, os dados censitários evidenciam ainda que a maioria dos produtores pobres norte-rio-grandenses desenvolve suas lavouras em "terras cansadas" de baixa produtividade, já que apenas $11,70 \%$ deles declarou fazer pousio ou descanso de solo e aproximadamente $10 \%$ usou algum tipo de adubo (químico ou orgânico) para recompor a fertilidade da terra entre um período de plantio e outro, sinalizando mais um elemento marcante do ambiente de precariedade no qual estavam inseridos.

Os números das "tabulações especiais" da segunda apuração do Censo Agropecuário 2006, destacados na Tabela 6, mostram também que uma pequena parte dos produtores mais pobres $(3,69 \%)$ usava algum tipo de irrigação em suas lavouras. Ademais, menos de $1 \%$ dos produtores familiares do Grupo B dispunham de silos para armazenar forragem para o rebanho nos períodos de escassez de pastos naturais. Tais carências tecnológicas deixam as atividades agropecuárias desenvolvidas pelos agricultores pobres altamente expostas às irregularidades do regime pluviométrico que caracteriza o espaço territorial do RN.

Aquino et al. (2014) explicam que o baixo padrão técnico apresentado pelos produtores pobres tem vários determinantes que vão desde a falta de financiamentos públicos ${ }^{11}$ até os limi-

11. No caso específico do RN, a falta de crédito rural é um problema que atinge a maioria dos agricultores pobres. Em 2006, segundo os dados do Censo Agropecuário (IBGE/SIDRA, 2012), 81\% dos produtores do estado não tiveram acesso ao crédito rural via bancos ou cooperativas. Registre-se, contudo, que entre os 7.951 agricultores 
S180 - Magnitude e Condições de Reprodução Econômica dos Agricultores Familiares Pobres no Semiárido Brasileiro: evidências a partir do Rio Grande do Norte

Figura 2. Percentual de estabelecimentos do Grupo B em relação ao recebimento de orientação técnica no Rio Grande do Norte - 2006

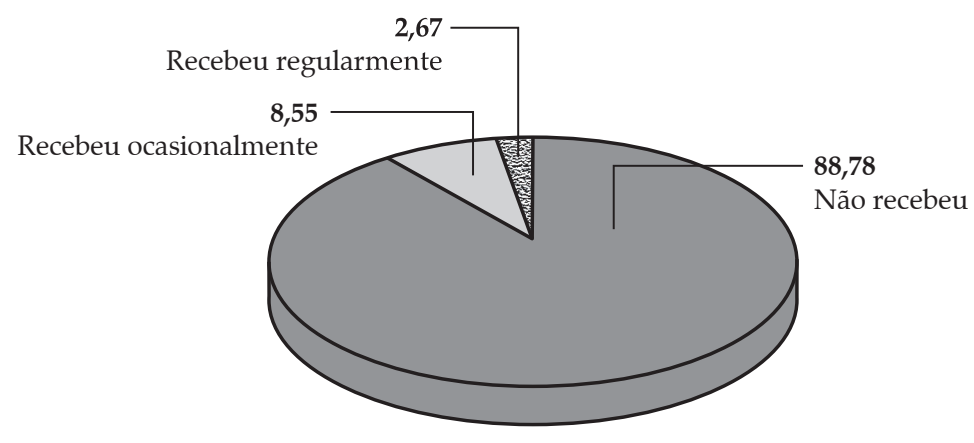

Nota: Dados organizados pelos autores.

Fonte: Tabulação especial da segunda apuração do Censo Agropecuário 2006 (IBGE/SIDRA, 2012).

tes colocados pela elevada taxa de analfabetismo dos chefes dos estabelecimentos. Todavia, mesmo admitindo a complexidade da questão, tudo indica que o quadro retratado pelas estatísticas censitárias é fortemente influenciado pela falta de assistência técnica à disposição dos produtores.

De fato, na Figura 2 observa-se que a falta de assistência técnica é um grande gargalo enfrentado pelos agricultores familiares pobres no RN. Do total de estabelecimentos do Grupo B potiguares, apenas $2,67 \%$ receberam assistência técnica regular e 8,55\% foram atendidos ocasionalmente por algum profissional de empresas públicas ou organizações não governamentais. Já $88,78 \%$ dos produtores desenvolveram suas atividades sem qualquer tipo de orientação técnica nas áreas de administração rural ou de produção vegetal e animal.

O limite imposto pela falta de assistência técnica e extensão rural, sem entrar no mérito da qualidade dos serviços e do tipo de atendi-

do Grupo B que obtiveram financiamentos (19\% do total), poucos devem ter alterado seu padrão tecnológico, seja pelos pequenos montantes dos empréstimos disponibilizados a esse público específico, seja pelo perfil das aplicações, que, conforme Holanda (2010), têm se concentrado basicamente na aquisição de bovinos, caprinos e ovinos. mento prestado, é particularmente relevante, pois inibe a disseminação entre os agricultores familiares pobres de tecnologias de produção "guardadas nas prateleiras" de instituições, tais como, por exemplo, a Universidade Federal Rural do Semiárido (Ufersa), a Empresa de Pesquisa Agropecuária do Rio Grande do Norte (Emparn) e outras entidades governamentais e não governamentais produtoras de conhecimentos voltados à melhoria das condições produtivas do campo.

Nesse sentido, percebe-se, por diferentes ângulos de observação, que os agricultores familiares potencialmente enquadráveis no Grupo B do Pronaf no RN desenvolvem suas atividades produtivas em condições extremamente desfavoráveis. Em função de suas "múltiplas carências produtivas" (de água, terra, educação, crédito, assistência técnica e tecnologias de produção), eles têm pouca chance de inovar e melhorar o desempenho de suas lavouras e de seus rebanhos no ambiente natural adverso do semiárido. O resultado, como será visto a seguir, vai ser a baixa produção agropecuária em anos de chuvas regulares e a completa exposição ao risco de perder as plantações e os pequenos rebanhos nos anos de secas prolongadas, fenômenos comuns em mais de $90 \%$ da área do território estadual. 
Figura 3. Valor médio da produção dos estabelecimentos agropecuários do Rio Grande do Norte - 2006 (Em R\$ 1,00)

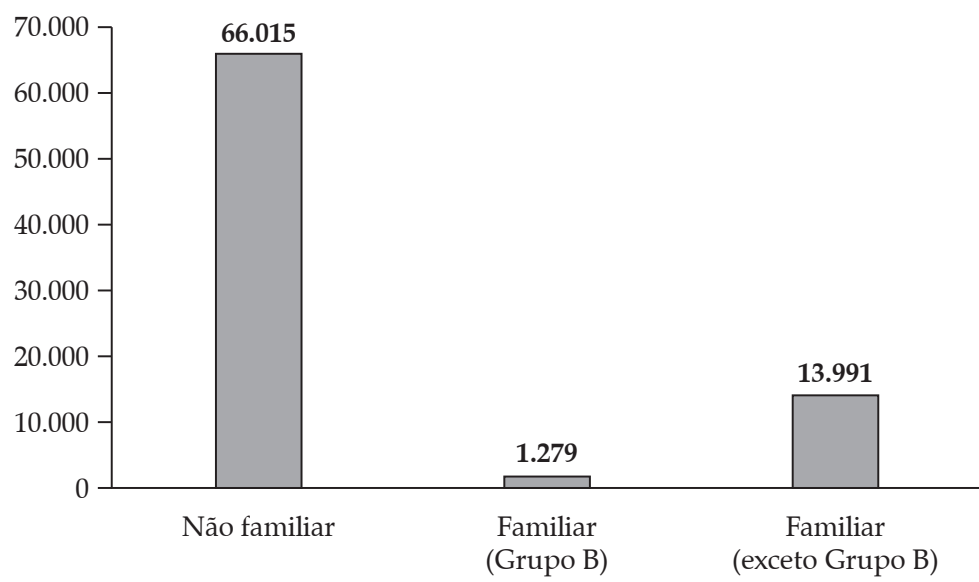

Nota: Dados organizados pelos autores

Fonte: Tabulação especial da segunda apuração do Censo Agropecuário 2006 (IBGE/SIDRA, 2012).

\subsection{Valor da produção total (VPT) ${ }^{12} \mathrm{e}$ receitas monetárias dos estabelecimentos do Grupo B}

A participação relativa dos estabelecimentos do Grupo B na riqueza agropecuária produzida no Rio Grande do Norte (RN) foi praticamente inexpressiva. Conforme os dados apurados pelo IBGE, do R $\$ 1$,1 bilhão produzido pelas atividades agropecuárias potiguares, apenas 4,17\% foram gerados nas pequenas propriedades dos agricultores familiares pobres. A maior parte do VPT $(63,15 \%)$ foi originada pelos estabelecimentos não familiares. Os assentados e os demais agricultores familiares com rendimentos superiores a $\mathrm{R} \$ 3$ mil, por sua vez, responderam por $32,68 \%$ da riqueza agropecuária proveniente dos estabelecimentos rurais norte-rio-grandenses (IBGE/SIDRA, 2012).

Quando se compara os valores de produção com o número total de estabelecimentos (VPT/ estabelecimentos do Grupo B), comprova-se que a capacidade de geração de riqueza de cada unidade de produção era extremamente baixa. Isto

12. O Valor da Produção Total (VPT) corresponde ao resultado da soma de três indicadores (IBGE, 2009): valor da produção vegetal, valor da produção animal e valor agregado da agroindústria (que é igual ao valor total dos produtos processados menos o valor das matérias-primas utilizadas). porque, como evidencia a Figura 3, cada estabelecimento do Grupo B gerou, em média, R\$1.279 durante todo o ano de 2006. Tal valor foi bem inferior ao verificado no interior dos estabelecimentos não familiares (R\$ 66.015) e no restante das propriedades familiares ( $\mathrm{R} \$ 1$ 13.991). Em outras palavras, mesmo que toda a produção animal e vegetal produzida pelos agricultores pobres fosse hipoteticamente convertida em dinheiro, o valor individual obtido por cada produtor nem de longe alcançaria a média dos demais produtores rurais localizados na área territorial pesquisada.

Considerando-se a representatividade numérica do Grupo B na estrutura agrária potiguar tanto no universo de estabelecimentos familiares (60\%) quanto no número de pessoas ocupadas (41\%) - constata-se que eles apresentam baixíssima produtividade e capacidade de geração de riqueza agropecuária. Pelo fato de 2006 ter sido um ano de chuvas regulares na maior parte do RN, com exceção apenas da mesorregião Agreste Potiguar (NEVES, MELO e SAMPAIO, 2011), tudo indica que a situação retratada é resultado das "múltiplas carências produtivas" mencionadas nas subseções anteriores. Ademais, como não há evidências de que o contexto de vulnerabilidade produtiva dos referidos produtores tenha sofrido 
S182 - Magnitude e Condições de Reprodução Econômica dos Agricultores Familiares Pobres no Semiárido Brasileiro: evidências a partir do Rio Grande do Norte

Tabela 7. Receitas obtidas pelos agricultores familiares do Grupo B do Pronaf no Rio Grande do Norte - 2006

\begin{tabular}{lcc}
\hline \multicolumn{1}{c}{ Receitas } & Valor (R\$ 1.000) & $\%$ \\
\hline Receita Agropecuária* & 24.581 & 25,25 \\
Outras Receitas & 72.774 & 74,75 \\
Receita Total & $\mathbf{9 7 . 3 5 5}$ & $\mathbf{1 0 0 , 0 0}$ \\
\hline
\end{tabular}

* A Receita Agropecuária foi obtida pelo somatório do valor das vendas de: produtos vegetais, animais em geral e seus produtos, animais criados em cativeiros (jacaré, escargô, capivara e outros), húmus e esterco.

Fonte: Tabulação especial da segunda apuração do Censo Agropecuário 2006 (IBGE/SIDRA, 2012).

Tabela 8. Composição das “Outras Receitas” obtidas pelos agricultores familiares do Grupo B do Pronaf no Rio Grande do Norte - 2006

\begin{tabular}{|c|c|c|}
\hline Fonte das outras receitas & $\begin{array}{c}\begin{array}{c}\text { Valor } \\
\text { (R\$ 1.000) }\end{array} \\
\end{array}$ & $\%$ \\
\hline Aposentadorias e pensões & 62.532 & 85,93 \\
\hline Programas sociais do governo & 5.906 & 8,12 \\
\hline Salários recebidos pelo produtor em atividades fora do estabelecimento e outras receitas & 2.607 & 3,58 \\
\hline Doações ou ajudas de parentes e amigos & 825 & 1,13 \\
\hline Produtos da agroindústria & 337 & 0,46 \\
\hline Pescado (capturado) & 159 & 0,22 \\
\hline Desinvestimentos & 140 & 0,19 \\
\hline Prestação de serviço para empresas integradoras & 88 & 0,12 \\
\hline Prestação de serviço de beneficiamento e/ou transformação de produtos agropecuários para terceiros & 82 & 0,11 \\
\hline Outras atividades não agrícolas realizadas no estabelecimento (artesanato, tecelagem etc.) & 64 & 0,09 \\
\hline Exploração mineral & 34 & 0,05 \\
\hline Total & 72.774 & 100,00 \\
\hline
\end{tabular}

Nota: Dados organizados pelos autores.

Fonte: Tabulação especial da segunda apuração do Censo Agropecuário 2006 (IBGE/SIDRA, 2012).

alguma mudança significativa pós-coleta dos dados do Censo pelos pesquisadores do IBGE, é bem provável que eles tenham sido as maiores vítimas da severa seca que assolou o estado em 2012 e 2013, destruindo as lavouras de sequeiro e dizimando boa parte do rebanho bovino constituído com os recursos do Pronaf ao longo de uma década ${ }^{13}$.

Independente de eventuais questionamentos sobre a atualidade ou não da fotografia apresentada pelo IBGE, o fato é que, com pouca ou nenhuma produção para comercializar no mercado, produtores pobres se tornam dependentes de outras fontes de renda para sobreviver. Tal

13. Em 2012, praticamente a totalidade dos 167 municípios do RN foram assolados pela estiagem, pois em $89 \%$ deles o regime de chuvas foi classificado como "muito seco" ou "seco". Em 2013, o quadro apresentou uma ligeira melhora, já que as chuvas ficaram dentro da média histórica em $33 \%$ do estado, mas, mesmo assim, em 55\% dos municípios a situação de seca permaneceu idêntica ao ano anterior (EMPARN, 2014a, 2014b). afirmação pode ser confirmada na Tabela 7. Nela, é possível perceber que a receita total do Grupo B no RN foi de pouco mais de R\$ 97 milhões. Desta, apenas $25,25 \%$ advinha de fontes agropecuárias, ou seja, era obtida por meio da venda da produção vegetal e animal da propriedade. Na verdade, são as outras receitas as principais responsáveis pela composição da maior parcela dos ingressos monetários verificados nos estabelecimentos dos agricultores familiares de subsistência.

Ao desagregar os indicadores apresentados, a Tabela 8 mostra que a maior parte das outras receitas obtidas pelos produtores do Grupo B era proveniente de aposentadorias e pensões $(85,93 \%)$ e da renda auferida através dos programas sociais do governo $(8,12 \%)$. Somadas, estas duas fontes de receitas representaram $94,05 \%$ do valor total das outras receitas obtidas por esses produtores. A elevada magnitude de tais percentuais indica que a subsistência dos "pronafianos" pobres está fortemente ligada às receitas oriundas das políti- 
cas de transferência de renda e, principalmente, da Previdência Rural. Essas rendas pagas mensalmente, em particular, cumprem um papel destacado na vida dos agricultores familiares pobres, complementando os orçamentos familiares nos anos de invernos regulares e garantindo as condições mínimas de sua subsistência nos períodos de estiagem.

As transferências governamentais funcionam, assim, como uma espécie de "colchão amortecedor" dos efeitos negativos das crises climáticas e das precárias condições de acesso ao mercado de trabalho fora das propriedades dos agricultores do Grupo B. Mas, se as transferências aumentam a resistência dos agricultores pobres à migração apesar de sua vulnerabilidade e de seu baixo desempenho produtivo, nem de longe elas resolvem o problema social relatado. Na verdade, elas apenas aliviam o quadro de pobreza que apresenta determinantes estruturais. A mudança da situação verificada requer a remoção das "múltiplas carências produtivas", elencadas ao longo do texto, que bloqueiam a capacidade dos produtores de gerar renda via atividades agropecuárias até mesmo nos anos de chuvas regulares.

Seguindo a mesma linha de interpretação do parágrafo anterior, Nascimento e Aquino (2010) destacam que ações governamentais de corte estritamente setorial, limitadas unicamente ao setor agropecuário, são necessárias, porém insuficientes para responder as necessidades da população rural que ocupa as áreas mais remotas do RN. Para esses autores, os principais desafios a serem enfrentados pelas políticas voltadas para o meio rural potiguar no século XXI consistem em, de um lado, fortalecer a agricultura e a produção de alimentos, e, de outro, melhorar as condições em que as atividades não agrícolas são desenvolvidas, de modo que, por estas duas vias, seja possível promover a pluriatividade como um importante caminho gerador de ocupação e renda para as famílias pobres.

Para além do aspecto produtivo, não se deve esquecer que as áreas rurais onde os produtores do Grupo B habitam ainda são "espaços de exclusão", em que boa parte dos direitos sociais bási- cos está longe de ser universalizada (GOMES DA SILVA, 2006; MARIANO e RIBEIRO, 2009). No meio rural potiguar falta saúde, educação fundamental de qualidade, segurança, lazer etc. Logo, esses problemas do entorno também precisam ser removidos em uma estratégia política de inserção produtiva dos agricultores de baixa renda.

Nesta perspectiva, conforme argumentam Delgado e Theodoro (2005), as medidas equalizadoras de desigualdade clamam por ações de política pública de dotação de "bens primários" (terra, água, qualificação profissional, renda, crédito, entre outros) e "bens públicos" (saúde, educação fundamental, habitação, segurança etc.) essenciais ao desenvolvimento humano com equidade. A combinação sinérgica de tais ações seria o caminho para elevar a produtividade econômica da agricultura familiar de subsistência e, ao mesmo tempo, melhorar a qualidade de vida no campo. Espera-se, então, que políticas governamentais recentes como o Programa Brasil Sem Miséria, lançado após a realização do Censo de 2006, estejam enfrentando esse desafio. Este assunto, no entanto, é tema que será explorado em um futuro próximo.

\section{Considerações finais}

A publicação das "tabulações especiais" da segunda apuração do Censo Agropecuário 2006 abriu novas perspectivas de estudo sobre a realidade do Brasil rural. A partir das inovações metodológicas adotadas, entre outros pontos, foi possível estudar aspectos da estrutura da agropecuária norte-rio-grandense que se encontravam escondidos por trás da expressão generalizante "agricultura familiar".

O recorte estatístico adotado revelou que a parcela majoritária dos agricultores familiares do Rio Grande do Norte (60\%), por serem extremamente pobres, eram enquadráveis no Grupo B do Pronaf. Tais produtores, com rendimentos "rebatidos" inferiores a R\$ 3 mil por ano, estavam distribuídos geograficamente em todo o território estadual. Porém, cabe observar que a maior parte 
S184 - Magnitude e Condições de Reprodução Econômica dos Agricultores Familiares Pobres no Semiárido Brasileiro: evidências a partir do Rio Grande do Norte

deles encontrava-se localizada nas microrregiões da Serra de São Miguel, Litoral Sul, Agreste Potiguar, Umarizal e Borborema Potiguar.

De modo geral, os estabelecimentos potencialmente enquadráveis no grupo de "pronafianos" pobres eram dirigidos, em sua maioria, por homens de idade avançada, que residiam nas próprias unidades de produção ou em áreas rurais próximas, apresentavam um elevado índice de analfabetismo e pouca participação em entidades de classe e, especialmente, em cooperativas.

Esses agricultores desenvolviam suas atividades em pequenas propriedades onde era registrado um acesso precário a fontes fixas de água. Estas ocupavam um contingente significativo de mais de 100 mil pessoas, predominantemente ligadas à família do produtor, que, sem tecnologias de produção apropriadas, sem crédito e praticamente sem assistência técnica, conseguiram gerar apenas um pequeno valor da produção a partir das atividades agropecuárias em um ano regular de chuvas, o que leva a refletir sobre a precariedade da situação vivenciada nos períodos de estiagem prolongada, como fora registrado em 2012 e 2013.

Nesse contexto, dispondo de pouca ou nenhuma produção para comercializar e inseridos em estruturas de mercado que dificilmente garantem a apropriação dos pequenos excedentes gerados, os agricultores do Grupo B se tornam dependentes de outras fontes de renda para sobreviver, com especial destaque para as receitas oriundas das aposentadorias rurais e dos programas sociais do governo. Essas receitas garantem um fluxo regular de dinheiro que assegura liquidez mínima nas propriedades, a qual alivia a precariedade das condições de reprodução econômica, contribuindo para manter as famílias produzindo e vivendo no campo.

A reversão do quadro de pobreza multidimensional apresentado requer um leque de políticas públicas integradas, visando remover as "múltiplas carências" (escassez de terra, água, educação, tecnologias, crédito, assistência técnica, entre outras) que bloqueiam as capacidades produtivas dos agricultores familiares pobres "dentro" dos estabelecimentos, as quais provavelmente foram agravadas com os dois anos consecutivos de secas que atingiram a região Nordeste de forma geral, e o RN, de forma particular. A mudança exige também a ampliação da oferta de bens públicos situados "fora" dos estabelecimentos, ou seja, nas áreas rurais onde reside a parcela majoritária do segmento pesquisado.

Ao desnudar esses aspectos da realidade agrária potiguar, ocultados por trás da noção globalizante "agricultura familiar", as evidências apresentadas contribuem para o avanço da discussão sobre o tema da heterogeneidade do setor rural no semiárido brasileiro. Análises comparativas mais apuradas envolvendo todos os grupos de produtores podem elucidar outros aspectos da diversidade que marca a categoria dos agricultores familiares de subsistência. Além disso, incursões a campo podem revelar se a ação governamental conseguiu alterar o quadro de pobreza apresentado pela fotografia censitária do IBGE, ou se a realidade permanece a mesma de 2006.

Portanto, ao contrário das teses que advogam o desaparecimento dos produtores familiares de menor porte no Brasil como algo inevitável, o caso estudado sinaliza para a necessidade de aprofundar o debate sobre a variedade de situações que caracterizam a população rural albergada nesse amplo segmento da agricultura brasileira. Ao que tudo indica, a precariedade das condições de reprodução econômica dos agricultores pobres é determinada por um conjunto complexo de fatores histórico-estruturais, não podendo ser associada apenas à variável climática e, muito menos, à suposta inviabilidade técnica de tais produtores. Nesse sentido, a compreensão adequada dessa temática dependerá, cada vez mais, da capacidade de a academia nacional redirecionar seu olhar multidisciplinar para o vasto grupo de agricultores até então "invisíveis" na base da pirâmide social do campo. 


\section{Referências bibliográficas}

AQUINO, J. R. et al. Dimensão e localização do público potencial do PRONAF " $B$ " no Brasil: uma análise a partir do Censo Agropecuário 2006. In: CONGRESSO BRASILEIRO DE ECONOMIA, ADMINISTRAÇÃO E SOCIOLOGIA RURAL, 49., 2011, Belo Horizonte/MG. Anais... Belo Horizonte/MG: SOBER, 2011. (CD-ROM).

et al. Dimensão e características do público potencial do Grupo B do PRONAF na região Nordeste e no estado de Minas Gerais. In: SCHNEIDER, S., FERREIRA, B. e ALVES, F. (Orgs.). Aspectos multidimensionais da agricultura brasileira: diferentes visões do censo agropecuário 2006. Brasília/DF: IPEA, 2014. p. 77-105. (Capítulo 3).

BASTOS, F. Ambiente institucional no financiamento da agricultura familiar. São Paulo: Polis; Campinas, SP: CERES - Centro de Estudos Rurais do IFCH UNICAMP, 2006.

BELIK, W. O financiamento da agricultura familiar no Brasil na década de 2000. In: CONGRESSO BRASILEIRO DE ECONOMIA, ADMINISTRAÇÃO E SOCIOLOGIA RURAL, 52., 2014, Goiânia/GO. Anais... Goiânia/GO: SOBER, 2014.

BNB. Nordeste do Brasil: sinopse estatística 2013. Fortaleza: Banco do Nordeste do Brasil, 2013.

COÊLHO, J. D. Agricultura familiar no Nordeste. Informe Rural ETENE/BNB. Fortaleza, ano 4, n. 5, p. 1-11, 2010.

CORREAA, V. P. e ORTEGA, A. C. PRONAF: Programa Nacional de Fortalecimento da Agricultura Familiar: qual o seu objetivo e público-alvo? In: CONGRESSO BRASILEIRO DE ECONOMIA E SOCIOLOGIA RURAL, 40., 2002, Passo Fundo/RS. Anais... Passo Fundo/RS: SOBER, 2002. (CD-ROM).

DELGADO, G. C. O setor de subsistência na economia brasileira: gênese histórica e formas de reprodução. In: JACCOUD, L. (Org.). Questão social e políticas sociais no Brasil contemporâneo. Brasília: IPEA, 2005. p. 19-50.

DELGADO, G. C. e THEODORO, M. Desenvolvimento e política social. In: JACCOUD, L. (Org.). Questão social e políticas sociais no Brasil contemporâneo. Brasília: IPEA, 2005. p. 409-435.

DEL GROSSI, M. E. e MARQUES, V. P. M. A. Agricultura familiar no censo agropecuário 2006: o marco legal e as opções para sua identificação. Estudos Sociedade e Agricultura. Rio de Janeiro, v. 18, n. 1, p. 127-157, abr./2010.
DEL GROSSI, M. E. Agricultura familiar no Censo Agropecuário 2006. (Documento em formato PowerPoint apresentado no 49․․ Congresso da Sociedade Brasileira de Economia, Administração e Sociologia Rural, realizado na cidade de Belo Horizonte/MG, em julho de 2011).

EMPARN. Análise das chuvas acumuladas nos municíioios do Rio Grande do Norte em 2012. Natal: Empresa de Pesquisa Agropecuária do RN, 2014a. Disponível em: $<$ http://189.124.135.176/monitoramento/2012/mapas/ mapaRN.htm >. Acesso em: 20 mar. 2014.

Análise das chuvas acumuladas nos municípios do Rio Grande do Norte em 2013. Natal: Empresa de Pesquisa Agropecuária do RN, 2014b. Disponível em: <http://189.124.135.176/monitoramento/2013/mapas/ mapaRN.htm > . Acesso em: 20 mar. 2014.

FAO/INCRA. Novo retrato da agricultura familiar: o Brasil redescoberto. Brasília, 2000.

FELIPE, J. L. A., CARVALHO, E. A. e ROCHA, A. P. B. Atlas Rio Grande do Norte: espaço geo-histórico e cultural. João Pessoa/PB:Grafset, 2006.

GOMES DA SILVA, A. Pobreza, qualidade de vida e segurança alimentar: as famílias rurais norte-riograndenses. In: GOMES, A. (Org.). Da mobilização às mudanças sociais: dinâmica das novas ruralidades do Nordeste brasileiro. São Paulo: Polis; Campinas/SP: CERES, 2006. p. 161-176.

. et al. Impactos do PRONAF B sobre o meio rural na região Nordeste. Natal/RN: UFRN/IICA/NEAD/ FUNPEC, 2007. 59p. (Relatório de Pesquisa).

GRAZIANO DA SILVA, J. Os desafios das agriculturas brasileiras. In: GASQUES, J. G., VIEIRA FILHO, J. E. e NAVARRO, Z. (Orgs.). A agricultura brasileira: desempenho, desafios e perspectivas. Brasília: IPEA, 2010. p. 157-183.

GUANZIROLI, C. E. PRONAF dez anos depois: resultados e perspectivas para o desenvolvimento rural. Revista de Economia e Sociologia Rural. Brasília, v. 45, n. 2, p. 301-328, abr.jun. 2007.

GUANZIROLI, C. H., BUAINAIN, A. M. e DISABBATO, A. Dez anos de evolução da agricultura familiar no Brasil: (1996 e 2006). Revista de Economia e Sociologia Rural. Piracicaba-SP, v. 50, n. 2, p. 351-370, abr.jun. 2012.

HELFAND, S. M., MOREIRA, A. R. B. e FIGUEIREDO, A. M. R. Explicando as diferenças de pobreza entre produtores agrícolas no Brasil: simulações contrafactuais com o censo agropecuário 1995-96. 
S186 - Magnitude e Condições de Reprodução Econômica dos Agricultores Familiares Pobres no Semiárido Brasileiro: evidências a partir do Rio Grande do Norte

Revista de Economia e Sociologia Rural. Piracicaba-SP, v. 49, n. 2, p. 391-418, abr./jun. 2011.

HOFFMANN, R. e NEY, M. G. Evolução recente da estrutura fundiária e propriedade rural no Brasil. In: GASQUES, J. G., VIEIRA FILHO, J. E. e NAVARRO, Z. (Orgs.). A agricultura brasileira: desempenho, desafios e perspectivas. Brasília: IPEA, 2010. p. 45-64.

HOLANDA, G. A. Instituições, agricultura familiar $e$ crédito rural: avaliação dos resultados do Pronaf B nos Territórios Rurais do Rio Grande do Norte. Natal, 2010. 103f. Dissertação (Programa de Pós-Graduação em Economia) - Centro de Ciências Sociais Aplicadas, Universidade Federal do Rio Grande do Norte, 2010.

IBGE. Censo Agropecuário 2006. Agricultura Familiar. Primeiros resultados. Brasil, Grandes Regiões e Unidades da Federação. Brasília/Rio de Janeiro: MDA/MPOG, 2009.

Censo Agropecuário 2006: Brasil, grandes regiões e unidades da federação - segunda apuração. Rio de Janeiro: MPOG/IBGE, 2012.

IBGE/SIDRA. Censo Agropecuário 2006: agricultura familiar - MDA/PRONAF (Lei no 11.326 de 24/07/2006). Rio de Janeiro: IBGE, 2012.Disponível em: < http:// www.sidra.ibge.gov.br/bda/pesquisas/ca/defaultMDA. $\operatorname{asp} ? z=p \& o=2 \& i=P>$. Acesso em: 26 out. 2012.

INSA. Estabelecimentosagropecuários dosemiáridobrasileiro. Campina Grande/PB: INSA/SIGSAB, 2014. Disponível em: <http://www.insa.gov.br/sigsab/static/themes/ v1/lib/elfinder/Arquivos/Publica\% C3\% A7\% C3\%B5es/ Estabelecimentos \% 20agropecu \% C3\% A 1rios \% 20 do\%20Semi\%C3\%A1rido_S\%C3\%ADntese\% 20(2006). pdf $>$. Acesso em: 5 set. 2014.

KAGEYAMA, A. A., BERGAMASCO, S. M. P. P. e OLIVEIRA, J. A. de. Novas possibilidades de pesquisa sobre a agricultura familiar no Brasil a partir do Censo de 2006. RevistaTecnologia E Inovação Agropecuária. São Paulo, p. 16-27, dez. 2008.

Uma tipologia dos estabelecimentos agropecuários do Brasil a partir do Censo 2006. Revista de Economia e Sociologia Rural. Piracicaba-SP, v. 51, n. 1, p. 105-122, jan./mar. 2013.

MAIA, G. B. S., ROITMAN, F. B. e DE CONTI, B. M. Pronaf B: evolução e metodologias. Informativo Técnico Agris BNDES. [S.1.], n. 2, p. 1-16, fev. 2012.

MAIA, M. M. Cara e coroa: o PRONAF B e os impactos na ocupação rural do município de Ceará Mirim. Natal, 2008. 94f. Dissertação (Mestrado em Ciências
Sociais) - Centro de Ciências Humanas, Letras e Artes, Universidade Federal do Rio Grande do Norte, 2008.

MAIA GOMES, G. Velhas secas em novos sertões: continuidade e mudanças na economia do semi-árido e dos cerrados nordestinos. Brasília: IPEA, 2001.

MARIANO, J. L. e RIBEIRO, F. F. Desenvolvimento rural sustentável em territórios do Rio Grande do Norte: uma análise multidimensional. In: CONGRESSO BRASILEIRO DE ECONOMIA, ADMINISTRAÇÃO E SOCIOLOGIA RURAL, 47., 2009, Porto Alegre/RS. Anais... Porto Alegre/RS: SOBER, 2009. (CD-ROM).

MATTEI, L. Mudanças nas regras de financiamento do PRONAF. Artigos mensais OPPA. Rio de Janeiro/UFRRJ/ CPDA, n. 17, p. 1-4, mar. 2008.

Evolução do crédito do PRONAF para as categorias de agricultores A e A/C entre 2000 e 2010. In: CONGRESSO DA SOCIEDADE BRASILEIRA DE ECONOMIA, ADMINISTRAÇÃO E SOCIOLOGIA RURAL, 49., Belo Horizonte/MG. Anais... Belo Horizonte/MG: SOBER, 2011. (CD-ROM).

MDA/SAF/PRONAF. Plano safra da agricultura familiar 2006/2007. Brasília: MDA/SAF, 2006. Disponível em: <http://www.mda.gov.br>. Acesso em: 22 nov. 2006.

MDA/SAF. Cartilha do Plano Safra da Agricultura Familiar 2013/2014. Brasília: MDA, 2013. Disponível em: < http:// www.mda.gov.br>. Acesso em: 10 jan. 2014.

NASCIMENTO, C. A. e AQUINO, J. R. Ocupação e renda das famílias rurais do Rio Grande do Norte no início do século XXI (2002-2008). Economia Política do Desenvolvimento. Maceió/AL, v. 3, n. 8, p. 7-27, maio/ ago. 2010.

NAVARRO, Z. A agricultura familiar no Brasil: entre a política e as transformações da vida econômica. In: GASQUES, J. G.; VIEIRA FILHO, J. E.; NAVARRO, Z. (Orgs.). A agricultura brasileira: desempenho, desafios e perspectivas. Brasília: IPEA, 2010. p. 185-209.

NEVES, J. A., MELO, S. B. e SAMPAIO, E. V. S. B. Análise pluviométrica do Rio Grande do Norte - período: 1963-2009. Natal: EMPARN, 2011. 71p. (Série Documentos, nº 39).

NEY, M. G. e HOFFMANN, R. Educação, concentração fundiária e desigualdade de rendimentos no meio rural brasileiro. Revista de Economia e Sociologia Rural. Piracicaba-SP, v. 47, n. 1, p. 147-182, jan./mar. 2009.

NUNES, E. M. e SCHNEIDER, S. Economia agrícola, instituições e desenvolvimento rural: uma análise 
comparativa da diversificação econômica do Polo Assú/ Mossoró (RN). Revista Econômica do Nordeste. Fortaleza/ CE, v. 43, n. 3, p. 561-584, jul./set. 2012.

PEREIRA JR., M. e MATOS FILHO, J. Desenvolvimento endógeno e reestruturação produtiva nos territórios rurais do Rio Grande do Norte. In: CONGRESSO BRASILEIRO DE ECONOMIA, ADMINISTRAÇÃO
E SOCIOLOGIA RURAL, 47., 2009, Porto Alegre/RS. Anais... Porto Alegre/RS: SOBER, 2009. (CD-ROM).

SOUZA, P. M. et al. Análise da evolução do valor dos financiamentos do Pronaf-Crédito (1999-2010): número, valor médio e localização geográfica dos contratos. Revista de Economia e Sociologia Rural. Piracicaba-SP, v. 51, n. 2, p. 237-254, abr.jun. 2013. 
